\title{
Design para a deficiência: Empatia no projeto de um aparelho auditivo com ênfase estético-funcional
}

\author{
Design for disability: Empathy in a hearing aid project with aesthetic-functional \\ emphasis
}

CUNHA, Julia Marina; Mestranda; Universidade Federal de Santa Catarina

juliamarinac@gmail.com

MERINO, Giselle Schmidt Alves Díaz; Doutora; Universidade Federal de Santa Catarina; Universidade da Região de Joinville

gisellemerino@gmail.com

MERINO, Eugenio Andrés Díaz; Doutor; Universidade Federal de Santa Catarina

eugenio.merino@ufsc.br

\section{Resumo}

No Brasil, mais de 2 milhões de pessoas possuem algum grau de deficiência auditiva (IBGE, 2015), parcela esta que necessita de algum dispositivo assistivo. Nesse sentido, o aparelho auditivo pode auxiliar a comunicação e inclusão de pessoas com deficiência. Porém, são projetados para serem invisíveis, produzidos em cores de pele, escondidos atrás da orelha. A estigmatização do usuário afeta sua participação social, autoestima e bem-estar. Esta pesquisa objetivou desenvolver uma proposta de aparelho auditivo com ênfase nas características estético-funcionais, procurando eliminar ou reduzir o estigma relacionado ao uso do aparelho. A pesquisa é de natureza teóricoaplicada e foi desenvolvida em duas fases (Fase 1 teórica e Fase 2 prática), utilizando o GODP como metodologia de projeto. Como resultado, desenvolveu-se um aparelho auditivo retroauricular personalizável com ênfase estético-funcional. Conclui-se que o design em projetos de Tecnologias Assistivas pode promover a autoestima e melhoria da qualidade de vida das pessoas com deficiência.

Palavras Chave: Design; Tecnologia Assistiva; Aparelho auditivo.

\begin{abstract}
In Brazil, more than 2 million people have some degree of hearing impairment (IBGE, 2015), a portion that needs an assistive device. In this sense, the hearing aid can help the communication and inclusion of people with disabilities. However, they are designed to be invisible, produced in skin colors, hidden behind the ear. Stigmatization of the user affects their social participation, selfesteem and well-being. This research aims to develop a proposal for hearing aids with emphasis on aesthetic-functional characteristics, seeking to eliminate or reduce the stigma related to the use of the device. This research has a theoretical-applied nature and was developed in two phases (Phase 1 theoretical and Phase 2 practical), using GODP as a design methodology. As a result, a customizable BTE hearing aid with aesthetic-functional emphasis has been developed. It is concluded that design in Assistive Technology projects can promote self-esteem and improve the quality of life of people with disabilities.
\end{abstract}

Keywords: Design; Assistive Technology; Hearing aid. 


\section{Introdução}

O papel do design para a transformação social vem sendo cada vez mais destacado nas reflexões sobre o tema. Papanek e Fuller (1972), chamam atenção para a necessidade de incluir as minorias nos processos de design. Bonsiepe (2005), destaca a importância de um design democrático, de participação da sociedade no projeto. Ainda, segundo Moraes (2010), o designer pode atuar como um agente de mudança social proativo.

A definição de deficiência vem sendo discutida nos últimos anos, a Organização Mundial da Saúde (WORLD HEALTH ORGANIZATION, 2011) passa a compreender deficiência como uma experiência vivida por todos os indíviduos em algum grau durante a sua vida. Diniz (2007), descreve a experiência da deficiência como resultado das limitações impostas pelo contexto social e ambiente vivido, e não das condições físicas do corpo.

Segundo dados da Organização das Nações Unidas (2011), cerca de $10 \%$ da população mundial possui alguma deficiência. No Brasil, os últimos dados estatísticos obtidos revelam que $6,2 \%$ da população convive com uma ou mais deficiências (intelectual, física, auditiva e visual) (IBGE, 2015). Parcela esta, que necessita de algum recurso de Tecnologia Assistiva.

A tecnologia assistiva é definida como uma esfera do conhecimento interdisciplinar que envolve produtos, recursos, metodologias, práticas e serviços que possuem como objetivo promover a funcionalidade de pessoas com deficiência ou incapacidade, oferecendo bem-estar, autonomia e qualidade de vida (BRASIL, Comitê de ajudas técnicas, 2009).

Os estudos em Tecnologia Assistiva (TA) vêm ganhando evidência nos últimos anos, em virtude da ascensão dos paradigmas de inclusão social e valorização da diversidade (RODRIGUES; ALVES, 2013), o que ocorre também devido ao gradativo envelhecimento da população associado à maior expectativa de vida (COLEMAN, 2006). O design de dispositivos assistivos, no entanto, ainda é voltado para servir um diagnóstico médico ou a deficiência, por vezes desconsiderando o indivíduo como um todo ou seu bem-estar (ROYEEN, 2015).

Segundo o IBGE (2015), mais de 2 milhões de brasileiros (1,1\% da população) possui algum grau de deficiência auditiva. Sendo a tecnologia assistiva socialmente interpretada como um facilitador em um meio incapacitante (DINIZ, 2007) o aparelho auditivo, classificando-se como uma, facilita a comunicação e inclusão de deficientes auditivos.

No projeto de aparelhos auditivos em específico, mantêm-se uma cultura de design para a deficiência pautada na discrição como prioridade, discrição esta que é obtida por meio da constante miniaturização dos aparelhos. Segundo Pullin (2011), o tamanho dos aparelhos auditivos compromete a sua performance, os dispositivos poderiam oferecer melhor qualidade sonora se não fossem limitados em tamanho. A estigmatização do usuário afeta sua participação social, autoestima e consequentemente seu bem-estar (WHO, 2011), portanto a importância de eliminar o estigma existente em torno do produto.

Considerando a deficiência como parte constitutiva da identidade individual e consequentemente a Tecnologia Assistiva o reflexo da mesma, esta pesquisa tem como objetivo desenvolver uma proposta de aparelho auditivo com ênfase nas características estéticofuncionais. Assim, questionando o padrão estabelecido de invisibilidade/camuflagem apresentado pelos produtos existentes e procurando eliminar ou reduzir o estigma de incapacidade relacionado 
ao uso de tecnologias assistivas (HUNT, 1966; GARLAND-THOMSON, 2017; WHO, 2011, INGSTAD e WHYTE, 1995).

\section{Procedimentos metodológicos}

Quanto a natureza, esta pesquisa pode ser classificada como teórico-aplicada, em relação ao conteúdo, pode ser classificado como artigo de análise onde os elementos são analisados em relação ao todo (MARCONI; LAKATOS, 2003). Referente aos objetivos, a pesquisa pode ser caracterizada como exploratória, constituindo um aprimoramento de ideias sobre o assunto em questão (GIL, 2002). De acordo com os procedimentos técnicos, caracteriza-se como pesquisa bibliográfica, (GIL, 2002).

Divide-se a pesquisa em duas fases principais:

Fase 1- Fundamentação teórica: Apresenta-se a fundamentação, com relação aos métodos pode-se citar, pesquisas nas bases de dados Science Direct, PubMed, Web of Science, Google Acadêmico, Periódicos Capes e Biblioteca Digital de Teses e Dissertações, utilizando as seguintes palavras-chave e as correspondentes em inglês: design, deficiência, aparelho auditivo, tecnologia assistiva, estigma e combinações das mesmas.

Fase 2- Pesquisa aplicada: Desenvolvimento de um produto por meio de análise das informações coletadas. Nesta fase, utiliza-se a metodologia GODP (Guia de Orientação para o Desenvolvimento de Projetos) para guiar o desenvolvimento prático do projeto. O GODP é uma metodologia configurada em oito etapas que se fundamentam na coleta de informações pertinentes ao desenvolvimento da proposta, ao desenvolvimento criativo, a execução projetual, a viabilização e verificação final do produto (MERINO, 2016). Esse desenvolvimento é embasado na definição dos Blocos de Referência, Produto, Usuário e Contexto.

As etapas do GODP estão distribuídas em 3 momentos, chamados Inspiração, Ideação e Implementação. Apresentam-se neste artigo, as etapas 1, 2, 3, 4 e 5 correspondentes a parte do momento Inspiração, Ideação e parte do momento Implementação. A etapa 6 não foi abrangida pois corresponde ao acompanhamento do produto no mercado.

Inspiração (Etapa 1): Nessa etapa, como parte da coleta de dados para inspiração utilizouse a ferramenta role-playing para simular a experiência do usuário. Para tanto fez-se uso de um (1) aparelho auditivo retroauricular, uma (1) câmera fotográfica, e um (1) bloco para anotações. Esse experimento foi realizado de modo assistemático.

Ideação (Etapas 2 e 3): Neste momento tem-se a definição dos requisitos de projeto, estes foram determinados de acordo com os fatores identificados na fundamentação teórica e divididos em três blocos de informação (produto, usuário e contexto) de acordo com Merino (2016). Neste momento ocorre também a geração e seleção das alternativas propostas.

Implementação (Etapas 4 e 5): Neste momento o produto final é detalhado e justificado.

$\mathrm{Na}$ figura a seguir (Figura 1) pode-se visualizar as etapas e momentos da metodologia GODP com as etapas contempladas em destaque, assim como os Blocos de Referência do Produto, Usuário e Contexto. 
Figura 1- Etapas do GODP e Blocos de Referência

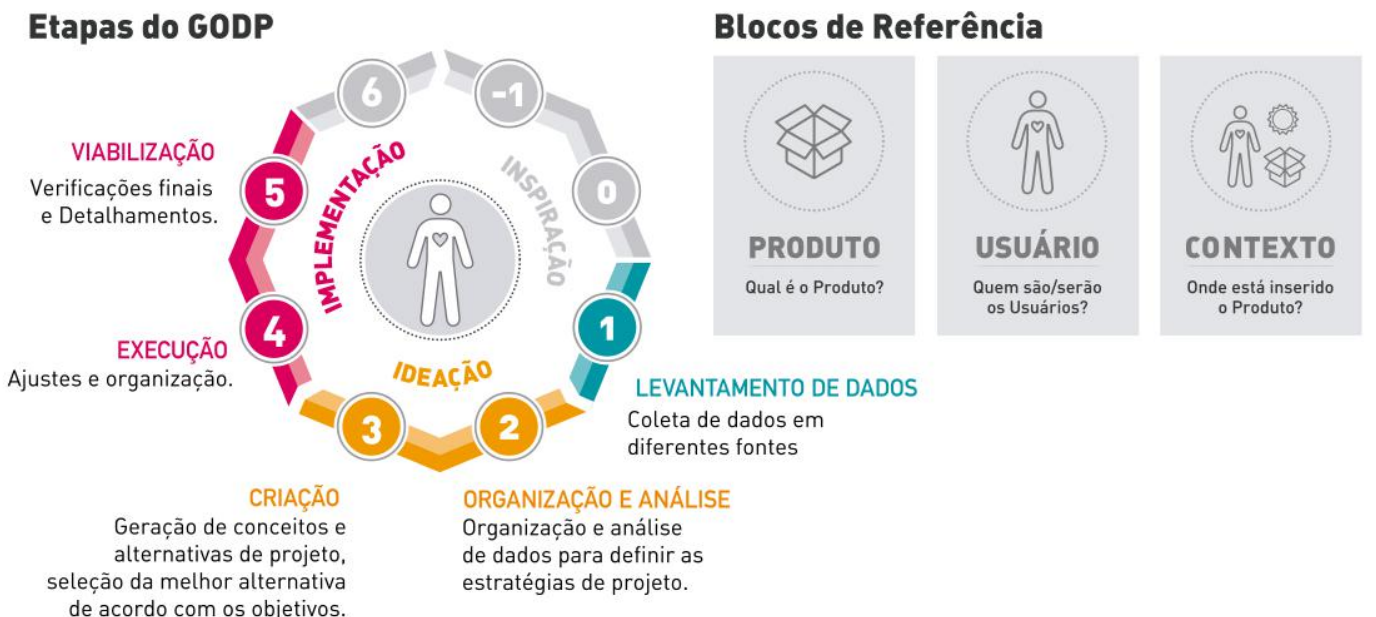

Fonte: Merino (2016)

\section{Fundamentação Teórica}

\subsection{Design para a deficiência}

O design para deficiência é, comumente, pautado na incapacidade dos indivíduos, o público alvo do produto é definido nos termos de uma deficiência específica a qual compartilham, por vezes deixando de lado a diversidade dos demais aspectos desse grupo (PULLIN, 2009).

As tecnologias assistivas são fortemente relacionadas a produtos exclusivamente médicos, o que limita o segmento e acaba gerando uma padronização estética, reduzindo os indivíduos aos estereótipos definidos pela deficiência (NEWELL, 2003). Quando o design de TAs é direcionado apenas para suprir uma necessidade médica, acaba deixando de lado o desejo humano do indivíduo de gerenciar dinamicamente sua identidade social. Sendo os seres humanos seres dinâmicos, os produtos incorporados ao seu corpo devem permitir a dinamicidade do ser, física, mental e socialmente (ROYEEN, 2015).

A taxa de abandono de TAs por usuários com diversas necessidades fica entre $50 \%$ e $56 \%$, $15 \%$ dos dispositivos não são nunca usados (M ØLLER; KETTLEY, 2017). O desafio do design no projeto de TAs é transformar a relação desses produtos com o usuário e com a sociedade, reduzindo o peso social (definido como a repercussão social na forma de atenção indesejada ou respostas negativas que um indivíduo pode receber quando vestido inapropriadamente) desses produtos.

Apenas por meio da criação de significados pessoais, pode-se integrar de forma bemsucedida uma tecnologia assistiva na vida de um indivíduo, cabe, portanto, ao projetista a compreensão dessas questões e a aplicação desse conhecimento no projeto.

\subsection{Aparelho auditivo e estigma}


O uso de aparelhos para melhorar a capacidade auditiva, data do século XVII, quando era relativamente comum o uso de objetos em forma de trompete, que amplificavam principalmente a fala e direcionavam para a orelha do usuário (BELTONE, 2016). A forma dos trompetes variava, porém mantinha-se o padrão amplo em uma extremidade e estreito na outra. Em geral eram dispositivos grandes, os quais os indivíduos deviam suportar com as mãos, próximos à orelha.

Já no século XVIII, inicia a preocupação com a estética do dispositivo e a aparência do usuário. Dentro das limitações tecnológicas da época, que não permitiam grandes reduções no tamanho dos aparelhos, os projetistas buscavam outros meios de camuflagem. Os dispositivos eram comumente incorporados em acessórios decorativos, como colares e tiaras, além disso havia uma tentativa de escondê-los em penteados no cabelo ou na própria barba (BERNARD BECKER MEDICAL LIBRARY, 2009).

Com a evolução da tecnologia e os meios de produção, atualmente observa-se uma forte tendência dos aparelhos auditivos disponíveis atualmente no mercado da busca pela invisibilidade ou camuflagem do produto quando utilizado, com o uso de cores que se aproximam do tom de pele e artifícios para que o produto fique escondido durante a sua utilização, o que gera um princípio de exclusão social e coloca a deficiência como algo a ser escondido. Em nível diretamente relacionado ao bem-estar e qualidade de vida da população, verifica-se que a maioria dos deficientes auditivos evitam a utilização de aparelhos justamente pelo estigma de exclusão criado em torno do uso das mesmas (HJ, 2006).

Para Crocker, Major, e Steele (1998), uma pessoa que é estigmatizada é uma pessoa cuja identidade social, ou participação em alguma categoria social, coloca em dúvida a sua humanidade, a pessoa é desvalorizada ou defeituosa perante os outros. Todos os indivíduos experienciam algum grau de estigmatização em algum momento de suas vidas, seja este, sentimentos de isolamento, alienação, exclusão, ou constrangimento resultante de ser diferente de alguma forma.

Dessa forma, deve-se reconhecer a dualidade de interpretações do uso de uma tecnologia assistiva como o aparelho auditivo: um facilitador ou uma ferramenta para a independência por um lado, mas também um símbolo de incapacidade ou dependência por outro (SCHERER, 2005).

Neste sentido, o usuário pode experienciar falhas na comunicação pela não utilização do aparelho auditivo e ao mesmo tempo sentir-se estigmatizado ao utilizá-lo, um dilema com fortes implicações para a autoestima de um indivíduo. Dessa forma, percebe-se que os aspectos sociais e pessoais da perda auditiva podem ter consequências para a saúde mental e física de uma pessoa (PARETTE; SCHERER, 2004).

O aparelho auditivo, como outras tecnologias assistivas, carrega símbolos, valores e significados subjetivos junto às suas características formais (PAPE; KIM; WEINER, 2002; WIELANDT ET AL. 2006), é preciso, portanto, compreender os significados para transformá-los.

\section{Pesquisa aplicada}

\subsection{Momento Inspiração (Etapa 1)}

Considerando os blocos de informação produto-usuário-contexto (MERINO, 2016), sendo 
produto o resultado do projeto, usuário aquele que se utiliza do produto, e contexto o meio onde ocorre a interação (Figura 1), apresentam-se os blocos de informação:

Produto: O aparelho auditivo ou Aparelho Amplificador Sonoro Individual (AASI) é definido como um dispositivo que amplifica a intensidade dos sons no ouvido do utente (MOORE $E$ POPELKA, 2016).

Usuário: É utilizado por deficientes auditivos com perda parcial, uma vez que para sua eficácia devem existir ainda células funcionais na orelha interna do indivíduo.

Contexto: O ambiente social e demais fatores físicos (ruído, umidade, entre outros).

A partir da definição desses blocos, foram realizadas análises dos diversos fatores envolvidos no projeto; no bloco produto analisou-se funcionamento e estrutura do aparelho auditivo, análises sincrônica e diacrônica; relacionando-se ao usuário, buscou-se compreender audição e deficiência auditiva, fatores de uso, antropometria e pesquisa de campo, esta envolveu questionário e entrevistas; sobre o bloco contexto, exploraram-se fatores físicos do ambiente de uso e utilizou-se da ferramenta de empatia apresentada a seguir para a compreensão dos aspectos sociais do ambiente.

\subsubsection{Design Empático}

É da natureza do ser humano analisar situações baseado nas próprias experiências e preconcepções do objeto ou fato (THOMAS, 2013), a mudança de perspectiva só ocorre quando o observador se coloca em condições contraditórias, portanto a importância de utilizar uma abordagem empática, principalmente em projetos de tecnologias assistivas. Design empático é uma abordagem de pesquisa em design direcionada para a construção do entendimento dos usuários e seu dia a dia com o fim de desenvolver um novo produto (POSTMA et al, 2012). Sendo o processo sensível não apenas aos aspectos funcionais, mas também ao contexto social vivenciado, resulta em produtos mais humanizados.

Dentro da psicologia empatia se refere a sensibilidade, a percepção do estado mental do outro (NILSSON, 2003). Cakmakli (2010) descreve empatia no contexto da pesquisa em design e o entendimento das necessidades dos usuários. Para o projetista, empatia é a capacidade de se imaginar como outra pessoa, geralmente o usuário do produto. Envolve reconhecimento e representação das características pessoais do usuário, estado emocional e ações.

Existem diversas abordagens para o processo empático, nesta pesquisa em específico, utiliza-se do role-playing (KOUPRIE E VISSER, 2009), que se dá por meio da simulação do contexto vivido pelo usuário. A imersão pode revelar pontos da vivência que de outra forma não seriam percebidos pelo projetista, além da compreensão afetiva que se tem ao ganhar empatia, segundo Leonard e Rayport (1997) essas técnicas inspiram a criação de produtos adequados às reais necessidades dos usuários.

Considerando o objetivo deste estudo, desenvolver uma proposta de aparelho auditivo com ênfase nas características estético-funcionais, buscou-se replicar as condições de uso do aparelho auditivo retroauricular no que diz respeito à sua visualidade. Para tanto, a projetista utilizou um aparelho retroauricular não funcional durante o período de 5 (cinco) dias, realizando 
suas atividades normalmente (Figura 2). Para a documentação da experiência foram utilizadas fotografias e anotações relativas à reaçãoไpercepção dos outros indivíduos ao se deparar com o aparelho auditivo e o estímulo emocional para o usuário, neste caso, a projetista.

Figura 2- Fotografias da utilização do aparelho auditivo retroauricular

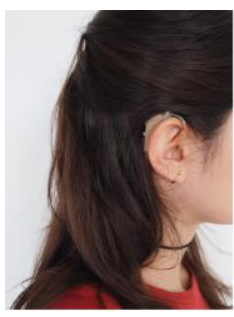

DIA 1

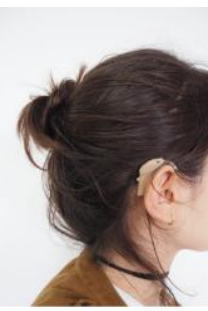

DIA 2

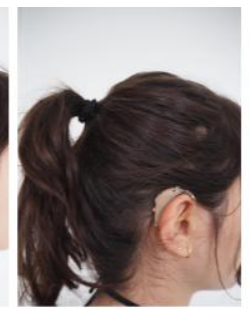

DIA 3

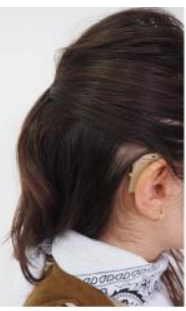

DIA 4

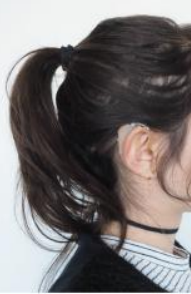

DIA 5

Fonte: os autores

Nota-se que os indivíduos em geral não procuram esconder a curiosidade e estranhamento em relação ao aparelho auditivo, independentemente do contexto. A reação emocional vivida era de desconforto e incômodo, resistindo diversas vezes ao impulso de retirar o aparelho auditivo ou escondê-lo. Além disso, há uma autoconsciência dos impactos da estética do aparelho auditivo na própria aparência.

\subsection{Momento Ideação (Etapas 2 e 3)}

A partir dessas análises, na etapa 3 da metodologia GODP definiram-se os requisitos de projeto, também enquadrados nos blocos de informação (Figura 3).

Figura 3- Requisitos de projeto

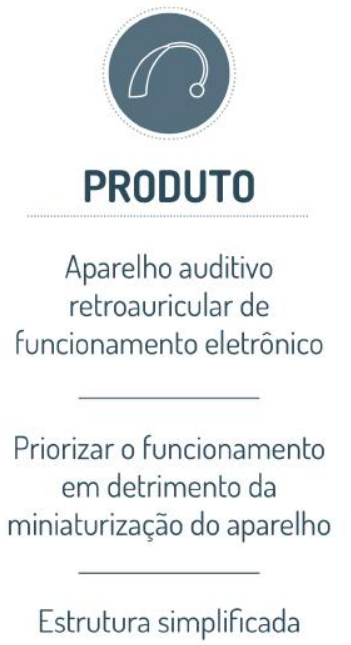

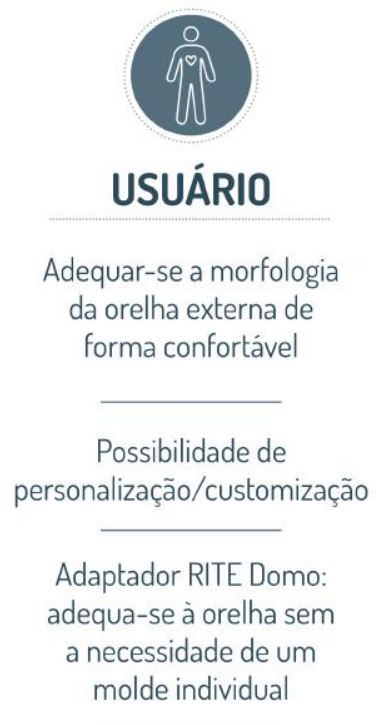

Sem gênero I Unissex

Fonte: os autores 
Dos requisitos do produto:

- Aparelho retroauricular de funcionamento eletrônico: considerando o modelo extremo em termos de visibilidade, no aparelho retroauricular a caixa onde são acomodados os componentes de funcionamento é externa, localizando-se atrás da orelha do usuário.

-Priorizar o funcionamento em detrimento da miniaturização: não prejudicar o funcionamento do aparelho na tentativa de torna-lo invisível.

-Estrutura simplificada: evitar complexidade desnecessária

Quanto aos requisitos advindos das necessidades dos usuários:

-Adequar-se a morfologia da orelha externa de forma confortável: considerando a anatomia da orelha externa e a antropometria.

-Possibilidade de personalização: destacando a expressão da própria individualidade.

-Adaptador Domo Aberto: O domo, ou adaptador RITE do aparelho auditivo, é a pequena peça em forma de sino de plástico na extremidade do tubo, é a peça que é inserida no canal auditivo do usuário (ROSS, 2004). O domo aberto torna o produto mais abrangente, eliminando a necessidade de um molde individual para cada usuário. $O$ adaptador domo é inserido na entrada do canal auditivo e adequa-se à diversos usuários.

-Sem gênero/unissex: Mantendo o direcionamento inclusivo, qualquer diferenciação neste sentido geraria também um princípio de exclusão.

Dos requisitos apresentados pelo contexto:

-Diferenciar-se das características formais clássicas, aproximando-se de um acessório: buscando um produto menos estigmatizante e mais inclusivo, conforme observado também durante a imersão.

-Não privar o usuário da realização de atividades específicas: evitando a exclusão, ou a sensação de limitação possivelmente imposta pelo aparelho auditivo.

A partir da definição dos requisitos de projeto realizou-se a geração de alternativas, com o suporte de painéis semânticos dos conceitos do produto.

O primeiro conceito definido, acolhedor/amigável, representa a sensação de conforto e segurança que deve ser transmitida pelo produto. O segundo conceito é também uma característica que deve estar evidente no produto, a possibilidade de personalização ou customização de acordo com a expressão individual do usuário. O conceito de singularidade devese à característica de valorização da diversidade, de inclusão da deficiência como parte desta, portanto salientando as particularidades do indivíduo de forma positiva, sendo refletido no produto.

Durante a geração das alternativas iniciais considerou-se essencialmente a forma, para posteriormente evoluir para as características estruturais e funcionais, de modo a não limitar o processo criativo. Considera-se também as possibilidades de arranho do produto na orelha, iniciando a inserção do conceito de customização (Figura 4). 
Figura 4 - Geração de alternativas

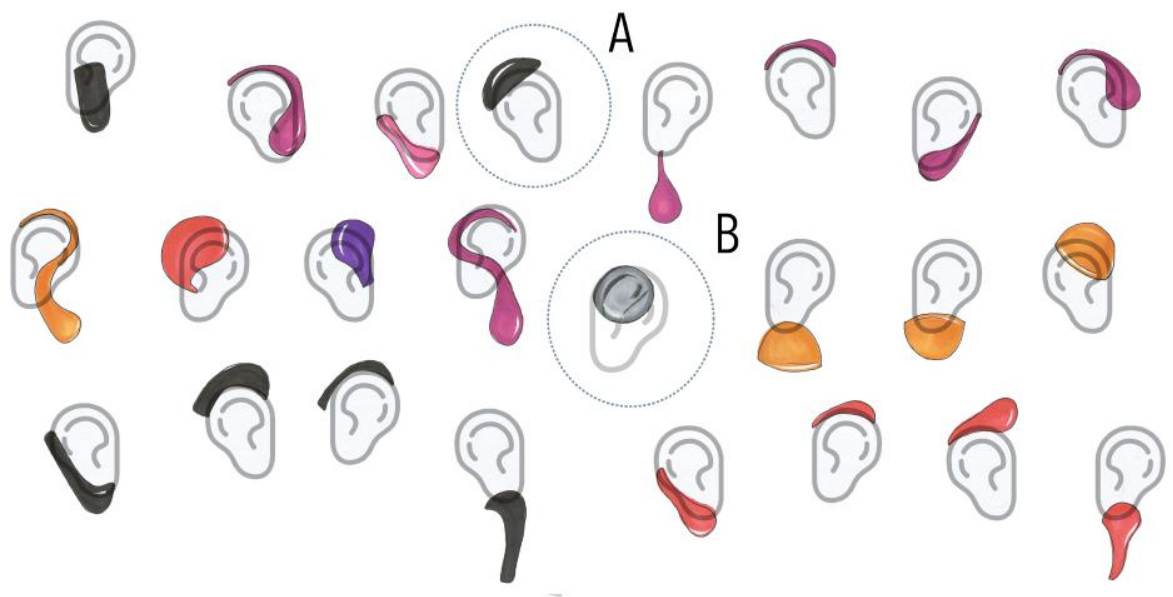

Fonte: os autores

As alternativas selecionadas inicialmente (destacadas na Figura 4) possuem formas mais simplificadas, versatilidade e potencial para customização, julgaram-se essas as alternativas que apresentavam características estéticas mais próximas das desejadas. Essas foram modeladas digitalmente em software 3D. Buscando analisar as alternativas de modo mais objetivo, utilizou-se da ferramenta de matriz de decisão a partir dos requisitos e conceitos definidos como critérios de escolha. A alternativa B obteve pontuação mais alta e foi, portanto, desenvolvida e detalhada.

Foram assim produzidos esboços das possibilidades de arranjo da alternativa selecionada (Alternativa B) na orelha, considerando sempre o produto em relação ao usuário (Figura 5).

Figura 5- Possíveis posições do produto
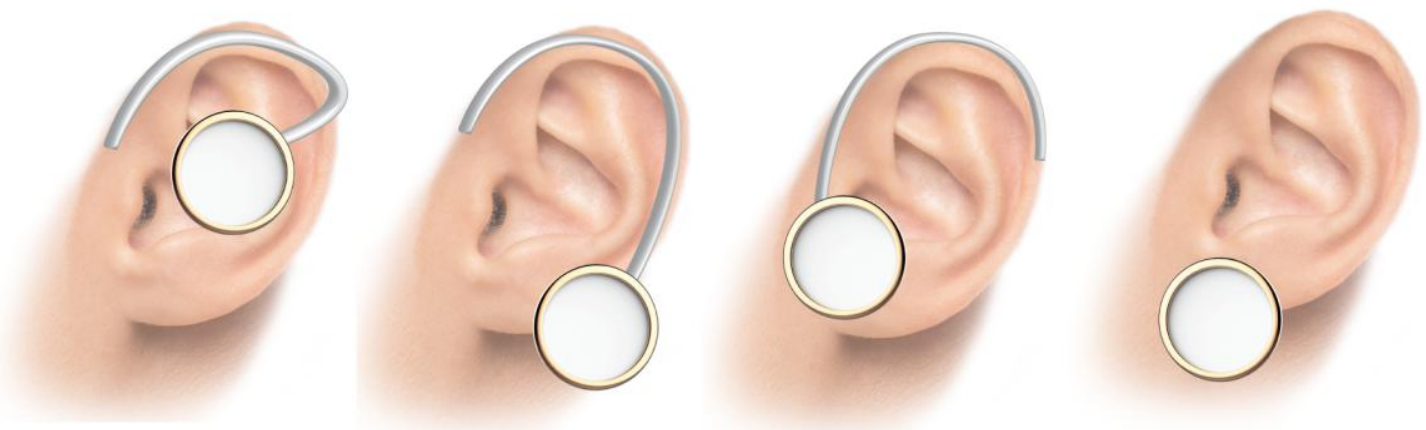

Fonte: os autores

\subsection{Momento Implementação (Etapas 4, 5 e 6)}

Neste momento apresenta-se o produto final e suas características (Figura 6).

A estrutura externa do produto final é composta por:

1- Arco flexível de suporte: É o que suporta o aparelho auditivo na orelha do usuário, por 
ser flexível pode ser ajustado de acordo com a preferência do mesmo. Além disso, permite variadas posições do aparelho na orelha. $\mathrm{O}$ arco flexível é produzido em aço e silicone.

2- Encaixe do arco no anel giratório: Onde o arco se liga ao anel intercambiável. liga/desliga.

3- Compartimento da bateria: Onde fica alojada a bateria, é também o comando

4- Anel intercambiável: É o que permite a personalização do aparelho, é também giratório, permitindo a mobilidade do arco.

5- Tubo de condução: Conduz o som amplificado para o receptor (adaptador) no canal auditivo do usuário.

6- Adaptador Domo aberto: Possui aberturas para que o som do ambiente possa passar. Isso evita o efeito de oclusão que seria a sensação de oco ou sons abafados, como sons de sua própria voz. Além de facilitar a adaptação dos usuários, uma vez que o som é mais natural desta forma (ROSS, 2004)

\section{Figura 6 - Estrutura produto final}

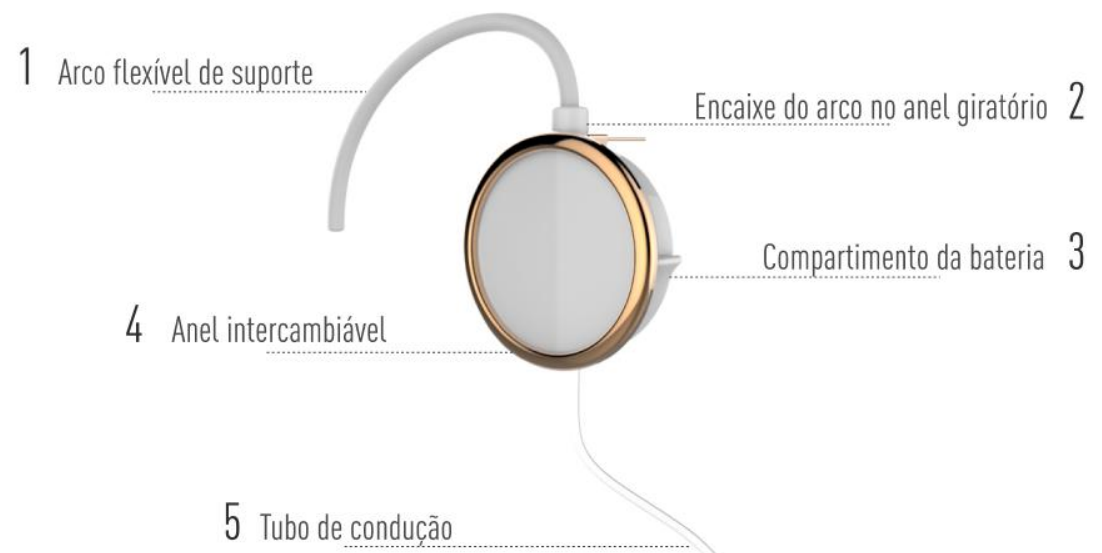

Adaptador Domo aberto 6

Fonte: os autores

Na figura a seguir (Figura 7) podem ser visualizados detalhes do produto, $(A)$ demonstra o anel giratório e pode ser visualizado o encaixe para o arco; em (B) tem-se o acessório complementar ou pino que permite que o aparelho seja utilizado como brinco; (C) demonstra a retirada do anel para possível colocação de outro; em (D) visualiza-se o compartimento da bateria aberto. 
Figura 7- Detalhes produto final

A
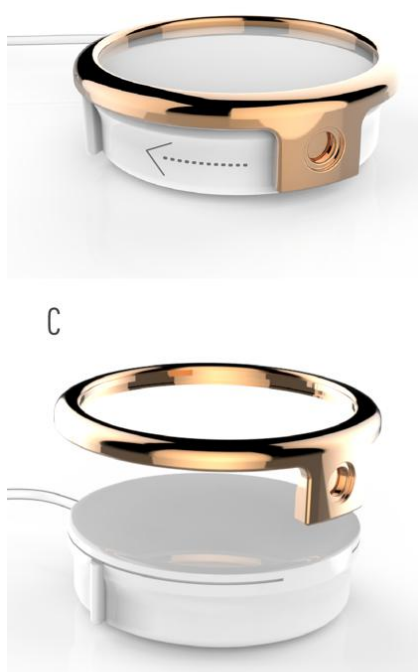

B

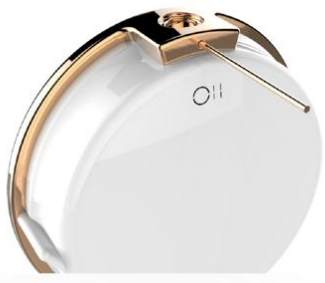

D

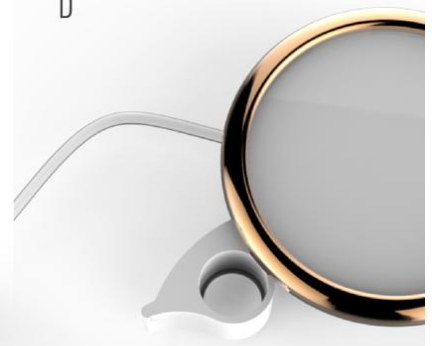

Fonte: os autores

O anel intercambiável permite a aplicação de diversas texturas, alterando a percepção do produto pelo usuário (Figura 8).

Figura 8 - Personalização produto final

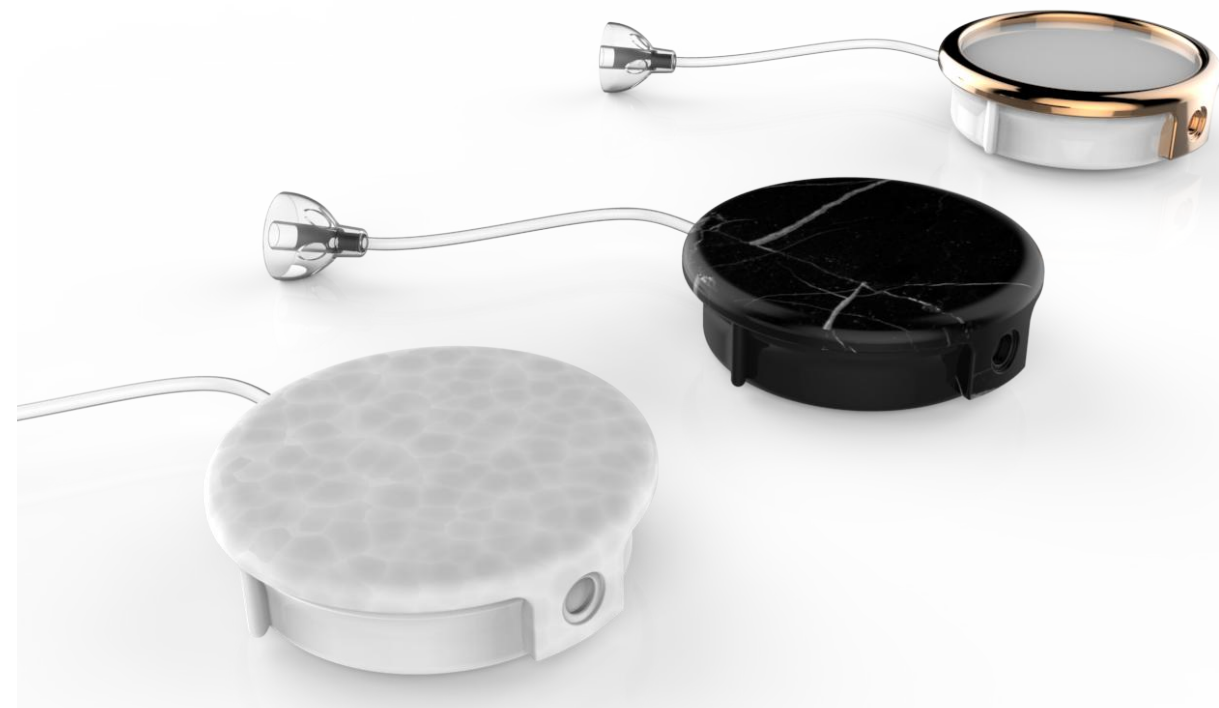

Fonte: os autores

A possibilidade de personalização do produto é uma forma de empoderamento do usuário, destacando as suas características individuais diversas e evitando as generalizações da deficiência. 
A escolha de uma tecnologia assistiva afeta diversas dimensões da vida de uma pessoa: saúde, autoestima e convívio social (PARETTE; SCHERER, 2004). Ao projetar dispositivos assistivos esteticamente agradáveis considera-se a pessoa como um todo, sendo saúde um estado de completo bem-estar, físico, mental e social (WORLD HEALTH ORGANIZATION, 2006).

É uma propensão universal do ser humano adornar, o uso de objetos decorativos para adorno do corpo ocorre desde o início da nossa existência. Objetos usados ou mantidos próximo ao corpo foram sempre e sempre serão escolhidos pelo oque eles dizem sobre o seu usuário, são adjetivos visuais. Sendo também o aparelho auditivo durante seu uso, um modo de expressão do indivíduo, e o que este expressa torna-se significativo por meio da identidade constituída em relação fluida com outras pessoas (M $\varnothing$ LLER; KETLEY, 2017). Ao desconectar o aparelho auditivo do estigma relacionado às tecnologias assistivas, altera-se não somente a relação do indivíduo com o produto, mas deste com a sociedade. Com a mudança dos atributos estéticos do aparelho auditivo o usuário pode criar uma relação prazerosa para com o mesmo, que exceda puramente a necessidade.

Figura 9 - Simulação do produto final em uso ${ }^{1}$

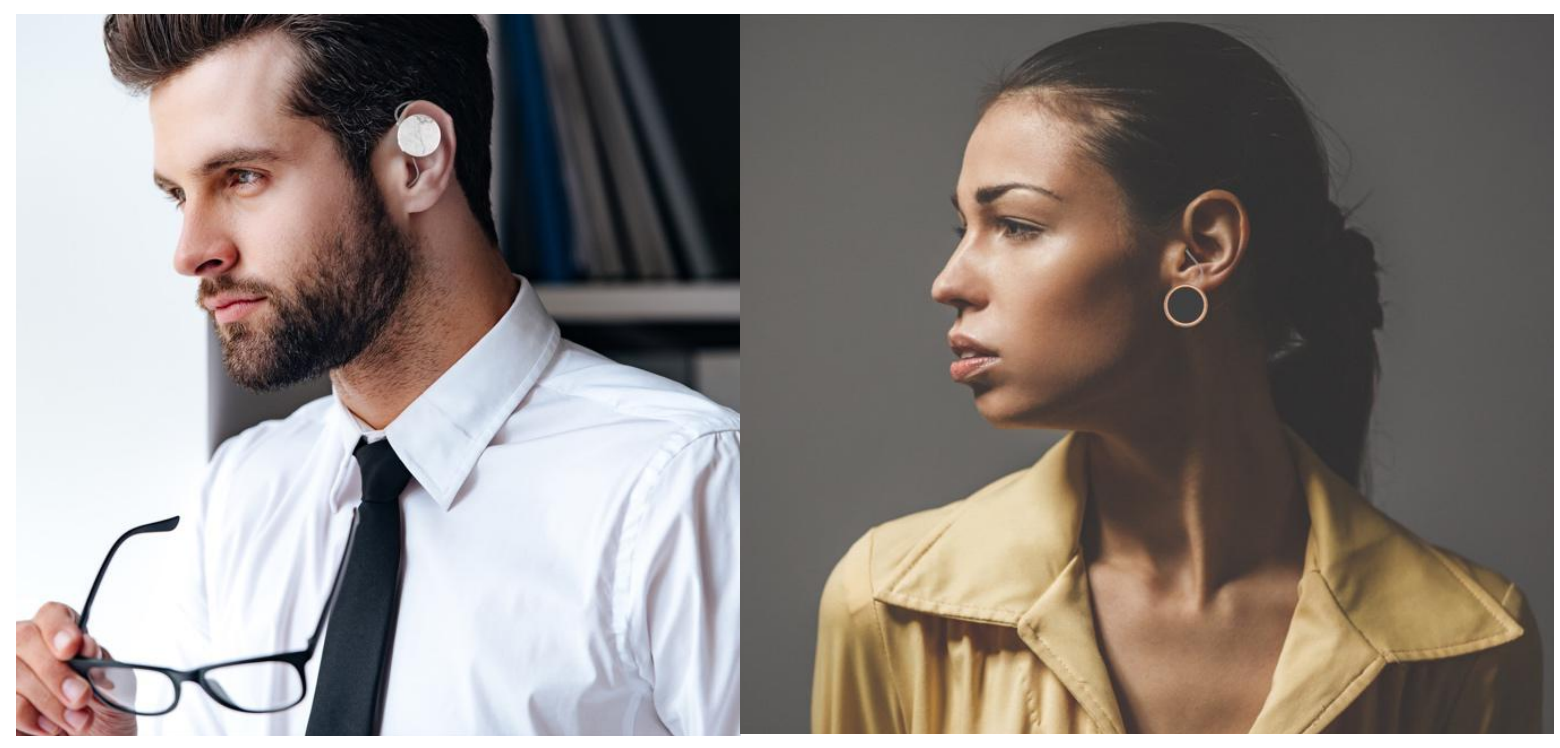

Fonte: os autores

\section{Conclusão}

A tecnologia assistiva é um fator essencial para a promoção da participação e integração das pessoas com deficiência na sociedade, possibilitando o convívio social e consequentemente melhorando a qualidade de vida dos usuários. No entanto, os produtos de tecnologia assistiva, apesar de facilitadores podem ser relacionados à incapacidade. Isto se deve em grande parte ao

\footnotetext{
${ }^{1} \mathrm{O}$ produto final desse projeto foi destaque na revista internacional de design Yanko Design e pode ser acessado em:
} 
padrão estabelecido de invisibilidade/camuflagem apresentado pelos produtos existentes, notado principalmente nos aparelhos auditivos, objeto deste projeto.

A utilização do GODP como metodologia centrada no usuário, possibilitou a análise dos fatores da relação produto-usuário de forma mais abrangente, assim como a abordagem empática utilizada no projeto destacou o caráter humano da pesquisa. O processo sensível não apenas aos aspectos funcionais, mas também ao contexto social vivenciado resulta em produtos mais humanizados.

Dessa forma, o produto resultante é um aparelho auditivo que procura reduzir o estigma relacionado à deficiência ao evitar a camuflagem do produto, tornando-o um modo de expressão ao permitir a personalização das suas características estéticas e flexibilidade no modo de uso. A relação do deficiente auditivo com o aparelho passa a ser mais afetiva, uma vez que a pessoa deve se identificar com o produto

A aplicação do design em projetos de tecnologias assistivas é, potencialmente, um modo de compreender o indivíduo como um todo, obtendo como resultado produtos que atendam não somente as necessidades dos usuários, mas considerem seus desejos e características individuais assim como a sua relação com a sociedade.

Além disso, esta pesquisa possui como intento, gerar questionamentos acerca das responsabilidades do design para transformação social, podendo auxiliar na mudança da relação da sociedade para com as tecnologias assistivas.

Como possíveis oportunidades de continuidade para este projeto podem ser citadas a validação do produto proposto com usuários reais, assim como a verificação do adequado funcionamento do aparelho auditivo.

\section{Agradecimentos}

Ao Núcleo de Gestão de Design e Laboratório de Design e Usabilidade da Universidade Federal de Santa Catarina (NGD/LDU) à Rede de Pesquisa e Desenvolvimento em Tecnologia Assistiva (RPDTA).

\section{Referências}

BELTONE. A quick history of hearing aids. Disponível em: <https://www.beltone.com/hearing-aidguides/hearing-aid- history.aspx>. Acesso em: 07 out. 2016.

BERNARD BECKER MEDICAL LIBRARY (Org.). Timeline of Hearing Devices and Early Deaf Education. Disponível em: <http://beckerexhibits.wustl.edu/did/timeline/>. Acesso em: 21 out. 2016.

BONSIEPE, Gui. Design and democracy. Design Issues, v. 22, n. 2, p. 27-34, 2006.

BRASIL. Subsecretaria Nacional de Promoção dos Direitos da Pessoa com Deficiência. Comitê de Ajudas Técnicas. Tecnologia Assistiva . Brasília: CORDE, 2009. 138 p. 
ÇAKMAKLI, Ayça. A good design= a good mate. In: 7th International Conference on Design \& Emotion. Design \& Emotion Society. 2010.

COLEMAN, Roger. Designing for our Future Selves. In Universal Design Handbook, W.F.E. Preiser \& E. Ostroff (Eds). McGraw-Hill, New York, 2001.

CROCKER, Jennifer; MAJOR, Brenda; STEELE, Claude. Social stigma. In: GILBERT, D. T; FISKE S. T.; LINDZEY, G. (Eds.). Handbook of social psychology. New York: McGraw-Hill.

DINIZ, Débora. O que é deficiência. São Paulo: Brasiliense. 2007. 80 p.

GARLAND-THOMSON, Rosemarie. Building a World with Disability in It. In: WALDSCHMIDT, Anne; BERRESSEM, Hanjo; INGWERSEN, Moritz (Ed.). Culture - Theory - Disability. Verlag, Bielefeld: Transcript, 2017. p. 51-62.

GIL, Antonio Carlos. Como elaborar projetos de pesquisa. 4. ed. São Paulo: Atlas, 2002.

HJ. HJ HEPORT. The Hearing Journal, v. 59, n. 11, p.8-8, nov. 2006. HOFMANN W. Rubber Technology Handbook, Hanser, New York, 1989.

HUNT, Paul (Ed.). Stigma: The experience of disability. London; Dublin [etc.]: G. Chapman, 1966.

IBGE. Pesquisa nacional de saúde 2013: Ciclos de Vida. Rio de Janeiro: Ibge, 2015.

INGSTAD, Benedicte; WHYTE, Susan Reynolds (Ed.). Disability and culture. Berkeley, Los Angeles, London: Univ of California Press, 1995.

KOUPRIE, Merlijn; VISSER, Froukje Sleeswijk. A framework for empathy in design: stepping into and out of the user's life. Journal Of Engineering Design, The Netherlands, v. 20, n. 5, p.437-448, out. 2009.

LEONARD, Dorothy; RAYPORT, Jeffrey.F., 1997. Spark innovation through empathic design. Harvard Business Review, 75 (6), 102-113.

MARCONI, Marina de Andrade; LAKATOS, Eva Maria. Fundamentos de metodologia científica. 5. ed. São Paulo : Atlas 2003.

MERINO, Giselle Schmidt Alves Díaz. GODP - Guia de Orientação para Desenvolvimento de Projetos: Uma metodologia de Design Centrado no Usuário. Florianópolis: Ngd/ Ufsc, 2016. Disponível em: <www.ngd.ufsc.br>. Acesso em: 05 fev. 2018

M $\varnothing$ LLER, Trine; KETTLEY, Sarah. Wearable health technology design: A humanist accessory approach. International Journal of Design, v. 11, n. 3, p. 35-49, 2017.

MOORE, Brian C.j.; POPELKA, Gerald R.. Introduction to Hearing Aids. In: POPELKA, Gerald R. et al (Ed.). Hearing Aids. Switzerland: Springer, 2016. p. 1-20.

MORAES, Dijon de. Metaprojeto: O design do design. São Paulo: Blucher, 2010.

NEWELL, Allen. Inclusive Design or Assistive Technology. In: CLARKSON, R; COLEMAN, S. Inclusive Design: Design for the Whole Population, Keates \& C. Lebon (Eds), Springer, London, 2003.

NILSSON, Peter. Empathy and Emotions: On the Notion of Empathy as Emotional Sharing. Umeå: Print \& Media, Umeå University, 2003. ORR, Heather; LOOPER, Matthew (Ed.). Wearing Culture. Boulder: University Press Of Colorado, 2014. 
ORGANIZAÇÃO DAS NAÇÕES UNIDAS (Bélgica) (Org.). Alguns Factos e Números sobre as Pessoas com Deficiência. 2011. Disponível em: <https://www.unric.org/pt/pessoas-com-deficiencia/5459> Acesso em 12 nov. 2017

PAPANEK, Victor; FULLER, R. Buckminster. Design for the real world. London: Thames and Hudson, 1972.

PAPE, T.L.B.; KIM, J; WEINER, B. The shaping of individual meanings assigned to assistive technology: a review of personal factors. Disability and Rehabilitation, v.24, n.1/2/3, p.5-20, 2002.

PARETTE, Phil; SCHERER, Marcia. Assistive Technology Use and Stigma. Education And Training In Developmental Disabilities, v. 3, n. 39, p.217-226, 2004.

POSTMA, Carolien E. et al. Challenges of doing empathic design: Experiences from industry. International Journal of Design, v. 6, n. 1, 2012.

PULLIN, Graham. Design meets disability. Usa: Mit Press, 2009.

RODRIGUES, Patrícia Rocha; ALVES, Lynn Rosalina Gama. Tecnologia Assistiva - Uma Revisão Do Tema. Holos, v. 6, n. 29, p.170-180, dez. 2013.

ROSS, Mark. The Occlusion Effect: What it is, and What to Do About it. Hearing Loss, jan. 2004.

ROYEEN, Lydia. The Style Evolution of Glasses: Acknowledging Well-being for Wearable Medical Device. The Open Journal Of Occupational Therapy, [s.I.], v. 3, n. 4, p.1-6, 1 out. 2015.

SCHERER, Marcia J.; GLUECKAUF, Rob. Assessing the Benefits of Assistive Technologies for Activities and Participation. Rehabilitation Psychology, [s.l.], v. 50, n. 2, p.132-141, 2005. American Psychological Association (APA).

THOMAS, Joyce. Empathic design: Research strategies. Australasian Medical Journal, [s.I.], v. 6, n. 1, p.1-6, 30 jan. 2013. Andrew John Publishing, Inc..

WIELANDT, Trish et al. Factors that predict the post-discharge use of recommended assistive technology (AT). Disability and Rehabilitation: Assistive Technology, v. 1, n. 1-2, p. 29-40, 2006.

WORLD HEALTH ORGANIZATION. Constitution of the World Health Organization. 2006. Disponível em: <http://www.who.int/governance/eb/who_constitution_en.pdf>. Acesso em: 02 dez. 2017. WORLD HEALTH ORGANIZATION. World Report on Disability. Malta: WHO, 2011. 